\title{
Characterisation of a new plasma-enhanced film to improve shear bond strength between zirconia and veneering ceramic
}

\author{
Sandro B. Bitencourt ${ }^{\mathrm{a}}$, Daniela M. dos Santos ${ }^{\mathrm{a}}$, Emily V.F. da Silva ${ }^{\mathrm{a}}$, Valentim A.R. Barão ${ }^{\mathrm{b}}$, \\ Elidiane C. Rangel ${ }^{c}$, Nilson C. da $\mathrm{Cruz}^{\mathrm{c}}$, Grace M. de Souza ${ }^{\mathrm{d}}$, Marcelo C. Goiato ${ }^{\mathrm{a}}$, \\ Aldiéris A. Pesqueira ${ }^{\mathrm{a}, *}$ \\ a Univ Estadual Paulista (UNESP), Aracatuba Dental School, Department of Dental Materials and Prosthodontics, R José Bonifácio, 1193, Araçatuba, São Paulo 16015- \\ 050, Brazil \\ ${ }^{\mathrm{b}}$ University of Campinas (UNICAMP), Piracicaba Dental School, Department of Prosthodontics and Periodontology, Av Limeira, 901, Piracicaba, São Paulo 13414-903, \\ Brazil \\ ${ }^{\mathrm{c}}$ Univ Estadual Paulista (UNESP), ICTS, Laboratory of Technological Plasmas, Av Três de Março, 511, Sorocaba, São Paulo 18087-180, Brazil \\ ${ }^{\mathrm{d}}$ University of Toronto, Faculty of Dentistry, Department of Clinical Sciences, 124 Edward Street, Toronto, Ontario M5G 1G6, Canada
}

\section{A R T I C L E I N F O}

\section{Keywords:}

Ceramics

Y-TZP ceramic

Shear bond strength

Aluminum oxide

Zirconium oxide

Fracture strength

\begin{abstract}
A B S T R A C T
The aim of this study was to develop and characterise a new plasma-enhanced chemical vapor deposition (PECVD) film for improving shear bond strength (SBS) between yttria-stabilised tetragonal zirconia (Y-TZP) and veneering ceramic. In total, 192 Y-TZP samples $(13 \times 5.4 \times 5 \mathrm{~mm})$ were divided into 6 groups: control - no treatment (C), airborne-particle abrasion with $27 \mu \mathrm{m}$ aluminum oxide particles $\left(\mathrm{Al}_{27}\right), 110 \mu \mathrm{m}$ aluminum oxide particles $\left(\mathrm{Al}_{110}\right)$, and $250 \mu \mathrm{m}$ aluminum oxide particles $\left(\mathrm{Al}_{250}\right)$, application of liner for zirconia $(\mathrm{L})$ and the PECVD film application (P). The Y-TZP surface was characterised by means of Scanning Electronic Microscopy (SEM), Energy-dispersive Spectroscopy (EDS), atomic force microscopy (AFM), surface profilometry and surfacefree energy (SFE). SBS between Y-TZP and veneering ceramic was tested before and after thermocycling $\left(20,000\right.$ cycles of 5 and $\left.55^{\circ} \mathrm{C}\right)$, and failure mode was also evaluated. Data were analysed by ANOVA and Tukey's HSD test $(\alpha=0.05)$. Data analysis showed that PECVD film had no effect on surface roughness of Y-TZP ( $p>0.05$ vs control), whilst the other groups presented higher roughness values $(p<0.05)$. All treatments increased SFE, except the $\mathrm{Al}_{27}$ group. The highest SBS was presented by the $\mathrm{P}$ group $(\mathrm{p}<0.05)$, and values were similar to those of the $\mathrm{Al}_{27}$ group $(\mathrm{p}=0.107)$. Mixed failures were prevalent in all groups, and premature failures were found only in Al groups after thermocycling. Whilst PECVD treatment did not affect Y-TZP surface roughness, high SBS between Y-TZP and the veneering layer was observed. Therefore, PECVD treatment is a promising alternative to improve the performance of bi-layer zirconia-based restorations.
\end{abstract}

\section{Introduction}

Nano-fluorapatite glass ceramic stands out for its excellent aesthetic qualities, such as translucence, fluorescence, opacity, shine and texture, mimicking the optical properties of the tooth structure [1, 2]. However, it presents a high degree of friability, high modulus of elasticity and low fracture toughness, which may result in internal fractures [3, 4]. With the objective of overcoming these limitations, yttria-stabilised tetragonal zirconia (Y-TZP) may be used as the core material due to its excellent fracture strength, given by the high crystalline content [5-7]. YTZP mechanical properties are indeed far superior to those of other dental ceramics [6, 8, 9]. However, as Y-TZP presents high opacity and reduced aesthetic characteristics, it has become the material of choice for the fabrication of single-unit and multiple fixed dental prostheses [10-12].

The combination of these ceramic materials generates a restoration that is both very resistant to occlusal forces, due to the Y-TZP infrastructure, and highly aesthetic, owing to the nano-fluorapatite glass ceramic used as a veneering material $[3,9,13,14]$. However, the interface between these two ceramic materials is one of the weakest and most critical aspects of the prosthesis, as shear bond strength (SBS) is directly influenced by the chemical inertia presented by Y-TZP [2, 7 , 15]. Thus, the chipping of the veneering ceramic is described in the literature as the greatest problem of all-ceramic restorations with a YTZP framework [5, 6, 16]. Many studies [2, 16, 17] have suggested the use of Y-TZP surface treatments to overcome this drawback, as the SBS

\footnotetext{
* Corresponding author at: José Bonifácio, 1193, Araçatuba, São Paulo, Brazil.

E-mail address: aldieris.ap@foa.unesp.br (A.A. Pesqueira).
} 
between the veneering ceramic and the zirconia core must be high enough to ensure long-term clinical success [7, 16].

Among these treatments, airborne-particle abrasion with aluminum oxide particles $\left(\mathrm{Al}_{2} \mathrm{O}_{3}\right)$ is the most frequently used, with high SBS results $[10,18]$. However, this surface treatment is controversial because whilst some researchers suggest that increased surface roughness is needed for micromechanical interlocking [7, 19], others claim that alumina-blasting generates stress zones and cracks on zirconia surfaces $[20,21]$. In addition to airborne-particle abrasion, the application of liners to zirconia surfaces is equally controversial [7, 22], because although high SBS has been reported [18], owing to better zirconia wetting [7], most studies show that this additional layer between zirconia and the veneering material increases the possibility of interfacial failures, compromising SBS [7, 18, 22].

The plasma film deposition treatment seems to be a promising alternative for the modification of chemical and physical properties of biomaterials [23, 24], control of bacterial growth [23], adhesion of restorations to the tooth substrate [23] and as a new treatment for ceramic substrates [22, 24]. Film deposition on zirconia by means of plasma-enhanced chemical vapor deposition (PECVD) consists of a combination of monomers and/or ionised gases, with a mixture of highly reactive particles, such as molecules, electrons, ions and free radicals, deposited on the Y-TZP surface after excitation by radiofrequency [21, 23, 25].

With the use of the hexamethyldisiloxane (HMDSO) monomer and gases such as argon (Ar) and methane $\left(\mathrm{CH}_{4}\right)$, it is possible to produce a film capable of improving the surface properties of zirconia [23, 25, 26], transforming its inert surface into a chemically active surface, without any structural damage to the surface [2, 25, 27]. This film is deposited on the zirconia surface by the PECVD treatment, affecting the hydrophilicity and wettability of the surface, and producing chemically active regions for bonding with other molecules [2, 21, 23, 25-27]. Despite these effects on the ceramic systems, there is no study that evaluated the combination of HMDSO, $\mathrm{Ar}$ and $\mathrm{CH}_{4}$ to improve the SBS between Y-TZP and a nano-fluorapatite glass ceramic.

Even though it is known that a long-lasting Y-TZP/veneering ceramic interface is a necessity for the clinical success of all-ceramic bilayer restorations, the best technique to improve the durability and predictability of those restorations has not yet been determined. Therefore, the aim of this study was to develop and characterise a new film using PECVD to improve the SBS between Y-TZP and veneering ceramic. Our hypothesis was that the PECVD treatment would improve the surface properties of Y-TZP and increase the SBS to the veneering ceramic.

\section{Materials and methods}

\subsection{Specimen fabrication}

One-hundred ninety-two rectangular $(13 \times 5.4 \times 5 \mathrm{~mm})$ specimens were fabricated from partially sintered Y-TZP blocks (ICE Zirkon Translucent, Zirkonzahn GmbH, Germany, Lot ZB3173H). Seventy-two specimens were used for surface characterisation $(n=14)$, and 120 specimens were used for SBS analysis $(n=20)$. The blocks were milled by the CAD/CAM system of Zirkonzahn according to the manufacturer's recommendation and sintered at $1500{ }^{\circ} \mathrm{C}$ in a sintering furnace (Zirkonofen $600 \mathrm{~V} / 2$, Zirkonzahn $\mathrm{GmbH}$, Gais, Germany), with a temperature rise time of $3 \mathrm{~h}$ (start temperature $=20^{\circ} \mathrm{C}$, heating rate $=8{ }^{\circ} \mathrm{C} / \mathrm{min}$ ); the temperature was maintained at $1500^{\circ} \mathrm{C}$ for $2 \mathrm{~h}$ before cooling (cooling rate $=8{ }^{\circ} \mathrm{C} / \mathrm{min}$, end temperature $=50^{\circ} \mathrm{C}$ ).

The specimens were polished after being sintered in an automatic grinder/polisher (AutoMet 250, Buehler, Lake Bluff, IL, USA), with constant water irrigation and manual pressure by means of siliconcarbide paper with grit \#320 (CarbiMet 2; Buehler) [25, 28]. Then specimens were ultrasonicated (Lavadora Ultrasonic Cleane, Unique, Indaiatuba, SP, Brazil) in deionised water for $1 \mathrm{~min}$, then cleaned in a bath of absolute ethanol solution for $5 \mathrm{~min}$, and ultrasonicated once again in deionised water for $1 \mathrm{~min}$ to remove impurities remaining on the surface [27].

\subsection{Experimental design}

Y-TZP specimens were randomised into 6 groups, according to the surface treatment: control - no treatment (C), airborne-particle abrasion with $27 \mu \mathrm{m} \mathrm{Al}_{2} \mathrm{O}_{3}$ particles $\left(\mathrm{Al}_{27}\right)$, airborne-particle abrasion with $110 \mu \mathrm{m} \mathrm{Al} \mathrm{O}_{3}$ particles $\left(\mathrm{Al}_{110}\right)$, airborne-particle abrasion with $250 \mu \mathrm{m}$ $\mathrm{Al}_{2} \mathrm{O}_{3}$ particles $\left(\mathrm{Al}_{250}\right)$, application of liner for zirconia ( $\mathrm{L}$ ) and PECVD film (P). The Y-TZP surface was characterised by means of SEM, EDS, AFM, surface profilometry and surface-free energy. SBS between Y-TZP and the veneering ceramic was tested before and after the thermocycling.

\subsection{Surface treatments}

\subsubsection{Group $C$}

No surface treatment was performed after the specimens were cleaned.

\subsubsection{Airborne particle abrasion}

For the groups that received airborne-particle abrasion, either $27 \mu \mathrm{m}$ (group $\mathrm{Al}_{27}$ - Aluminum Oxide, Danville Materials, Carlsbad, CA, USA), $110 \mu \mathrm{m}$ (group $\mathrm{Al}_{110}$ - Famox, Polidental ${ }^{\circledR}$ Ind. e Com. Ltda, Cotia, SP, Brazil) or $250 \mu \mathrm{m}$ (group $\mathrm{Al}_{250}$ - Famox, Polidental ${ }^{\oplus}$ Ind. e Com) aluminum oxide particles were placed in a micro-blaster (Basic Master; Renfert GmbH, Hilzingen, Germany) and applied to zirconia surfaces under a pressure of $0.4 \mathrm{MPa}$ for $20 \mathrm{~s}$, at a distance of $10 \mathrm{~mm}$ perpendicular to the surface, with circular movement to ensure blasting of the entire surface of the specimen [29].

\subsubsection{Group $L$}

The application protocol rigorously followed the manufacturer's instructions. The liner powder (IPS e.max Ceram ZirLiner; Ivoclar Vivadent, Amherst, NY, USA) was mixed with the respective liquid (Build-up Liquid; Ivoclar Vivadent) until a creamy consistency was obtained, then applied over the surfaces of the specimens and fired according to the manufacturer's recommendations at $960^{\circ} \mathrm{C}$ as maximum temperature (Table 1 ).

\subsubsection{Group $P$}

The specimens were subjected to PECVD treatment in a steel reactor (Laboratory of Technological Plasmas, Institute of Science and Technology/UNESP, Sorocaba, SP, Brazil). Before the film deposition process, the specimens were cleaned by sputtering of the surfaces in $\mathrm{Ar}$ plasma for $10 \mathrm{~min}$. The sputtering was performed at a pressure of $20 \mathrm{~Pa}$ of Ar, with a $70 \mathrm{~W}$ radiofrequency signal of $13.56 \mathrm{MHz}$ applied to the inferior electrode (sample-holder), whilst the superior electrode

Table 1

Firing conditions of veneering porcelain and liner as instructed by the manufacturer.

\begin{tabular}{|c|c|c|c|c|c|c|}
\hline Firing step & Start temperature $\left({ }^{\circ} \mathrm{C}\right)$ & Dry time (min) & Heat rate $\left({ }^{\circ} \mathrm{C}\right)$ & Final temperature $\left({ }^{\circ} \mathrm{C}\right)$ & Holding time (min) & Vacuum \\
\hline Liner & 403 & 4 & 40 & 960 & 1 & Yes \\
\hline Nano-fluorapatite & 403 & 4 & 40 & 750 & 1 & Yes \\
\hline
\end{tabular}


remained grounded. After the sputtering, the reactor was prepared for the PECVD film deposition conditions. The application of the PECVD was performed with a base pressure of $3.4 \mathrm{~Pa}$, with a mixture of $78 \%$ $\mathrm{CH}_{4}, 14 \% \mathrm{HMDSO}$ and $8 \% \mathrm{Ar}$, with a $250 \mathrm{~W}$ radiofrequency signal of $13.56 \mathrm{MHz}$ applied to the superior electrode. The inferior electrode received $500 \mathrm{~V}$ negative continuous tension by means of an autotransformer (Variac) during the entire process. The total pressure was maintained at a constant $9.2 \mathrm{~Pa}$ during $30 \mathrm{~min}$ of deposition. After this period, the HMDSO and $\mathrm{CH}_{4}$ gas valves were closed, and only the argon was maintained in the reactor for $8 \mathrm{~min}$, with all other conditions maintained equally. The veneering ceramic was applied $24 \mathrm{~h}$ after this treatment in all specimens.

After the treatment procedure, half of the samples were stored in distilled water at room temperature for $24 \mathrm{~h}$, and half of the samples were thermocycled before the SBS test.

\subsection{Characterisation of the Y-TZP surface}

\subsubsection{Scanning electronic microscopy and energy-dispersive spectroscopy}

Two additional specimens of each group $(n=2)$ were used for SEM analysis (JSM 610LA, JEOL, Tokyo, Japan) for characterisation of the surface before and after the surface treatments. Micrographs with $2000 \times$ and $10,000 \times$ magnifications were obtained. Characterisation of the elemental chemical composition was performed in small volumes, in the order of $1 \mu \mathrm{m}^{3}$, by means of EDS, with and without the surface treatments [25].

\subsubsection{Atomic force microscopy}

An atomic force microscope (Park NX10 AFM, Park Systems Inc., Suwon, Korea) was used to characterise the surface topography of specimens before and after surface treatment $(n=2)$. Images of $20 \times 20 \mu \mathrm{m}$ were obtained by the true non-contact mode. Gwyddion (Gwyddion v2.37; GNU General Public License) software was used to process the images.

\subsubsection{Surface profilometry}

Surface roughness was analysed $(n=10)$ by means of a surface contact profilometer (Dektak d-150; Veeco Instruments Inc., NY, USA). Three readings were performed on each specimen. The Ra (average roughness), Rq (root mean square roughness), Rt (maximum height of the profile) and $\mathrm{Rz}$ (average maximum height of the profile) values were measured with scanning of $300 \mu \mathrm{m}$ and a time constant of $12 \mathrm{~s}$ [25].

\subsubsection{Surface-free energy}

The surface-free energy was evaluated by measurement of the contact angle of the untreated/treated Y-TZP surfaces by means of a goniometer (Ramé-Hart 100-00; Ramé-Hart Instrument Co., Succasunna, NJ, USA) associated with software (DROPimage Standard, Ramé-Hart Instrument Co.) and the sessile drop technique $(n=10)$ [25]. Twenty readings were performed on each specimen: 10 readings determined the contact angle of the polar component (deionised water) and 10 determined the contact angle of the dispersive component (diiodomethylene) with the zirconia surface. The SFE was evaluated by the Owens-Wendt method with both contact angle (polar and dispersive) values [2].

\subsubsection{Shear bond strength}

For the SBS test, a nano-fluorapatite glass ceramic (IPS e.max Ceram, Ivoclar Vivadent, Lot K08699, J27560) was applied over the 120 Y-TZP samples ( $n=20$ /group) by the condensation method and according to the manufacturer's instructions for the preparation of the mass, condensation, temperature and firing time (Table 1). The sintering furnace (Programat P300, Ivoclar Vivadent) used was recommended by the ceramic manufacturer. The veneering ceramic was applied manually in the form of a rectangle with 3-mm height, 5.4-mm width and 4-mm thickness, following the Schmitz-Schulmeyer method [30] for SBS analysis between the two materials. Two layers were applied to obtain the final specimen dimension. Due to the glass ceramic contraction after the firing, the ceramic was applied twice to obtain the necessary size. Specimens were stored in distilled water at room temperature.

Twenty-four hours after the application of the veneering ceramic, 60 specimens ( $n=10 /$ group) were subjected to the SBS test in a universal testing machine (Instron Model 4400 Universal Testing System, Instron Corporation, Norwood, MA, USA) with a crosshead speed of $1 \mathrm{~mm} / \mathrm{min}$ with the help of a chisel in the interface between the two materials [31]. The load at fracture was recorded and determined in MPa based on the bonding interface area.

The remaining 60 specimens $(n=10 /$ group) were subjected to thermocycling (Model MSCT-3, Convel, Araçatuba, SP, Brazil) according to the following parameters: 20000 baths of $30 \mathrm{~s}$ and the temperature varying between 5 and $55^{\circ} \mathrm{C}$ [32]. Samples were then subjected to the SBS test following the same methods as previously described.

The mode of failure between Y-TZP and veneering ceramic was evaluated by stereomicroscopy (SteREO Discovery V20, Carl Zeiss MicroImaging GmbH, Göttingen, Germany) and was classified and quantified as adhesive in the zirconia/veneering ceramic interface or as cohesive or mixed failure in the interface between zirconia and veneering ceramic [2]. Representative specimens were covered with gold and mounted over aluminum stubs for the SEM analysis. SEM was used to obtain micrographs of the failure modes presented by each experimental group at $25 \times$ and $100 \times$ magnification (JSM 5600LV, JEOL, Tokyo, Japan).

\subsubsection{Statistical analysis}

One-way analysis of variance (ANOVA), with the independent variable being surface treatment in 6 levels, was used to investigate the effects of the treatments on surface roughness and surface-free energy of Y-TZP. Two-way ANOVA, with the independent variables being surface treatment (6 levels) and aging (2 levels), was carried out to verify the influence of surface treatments, thermocycling and their interaction on the SBS between Y-TZP and veneering ceramic. Tukey's HSD test was used to compare the mean values among the groups. Partial Eta Squared $\left(\eta_{\mathrm{p}}{ }^{2}\right)$ was used to estimate the effect size. With a sample size of 10 in the SBS test (our primary dependent variable), a large size effect $\left(\eta_{\mathrm{p}}{ }^{2}>0.26\right)$ was obtained $\left(\eta_{\mathrm{p}}{ }^{2}=0.381, \mathrm{p}<0.001\right)$. Statistical software (SPSS version 20.0 - Statistical Package for the Social Sciences, IBM Corporation, Armonk, NY, USA) was used, and all tests were conducted at a significance level of $5 \%$.

\section{Results}

\subsection{Surface characterisation}

SEM analysis showed evidence of a homogeneous surface for untreated (control) group C (Fig. 1A). Samples treated with airborneparticle abrasion $\left(\mathrm{Al}_{27}, \mathrm{Al}_{110}\right.$ and $\left.\mathrm{Al}_{250}\right)$ had surfaces covered with peaks and valleys characteristic of the mechanical action of the $\mathrm{Al}_{2} \mathrm{O}_{3}$ particles, with $\mathrm{Al}_{27}$-treated samples presenting the greatest topographical alterations among the blasted groups (Fig. 1B-D), due to the aluminum particle impregnation. PECVD-treated samples showed a homogenous coverage of the entire surface with globular formations (Fig. 1F). EDS analysis showed the presence of alumina peaks for the $\mathrm{Al}_{27}$-treated samples, silicon ( $\mathrm{Si}$ ) and iron ( $\left.\mathrm{Fe}\right)$ in the PECVD-treated samples and the underlying zirconia for all groups (Fig. 1A-F).

The 3-D images obtained through AFM analysis indicated the presence of tetragonal crystals on the surfaces of group C (Fig. 2A), whilst valleys and peaks were observed over the entire surface in the $\mathrm{Al}_{27}$, $\mathrm{Al}_{110}$ and $\mathrm{Al}_{250}$ groups (Fig. 2B-D), caused by the impregnation and blasting with the $\mathrm{Al}_{2} \mathrm{O}_{3}$ particles. The treatment with liner resulted in a 

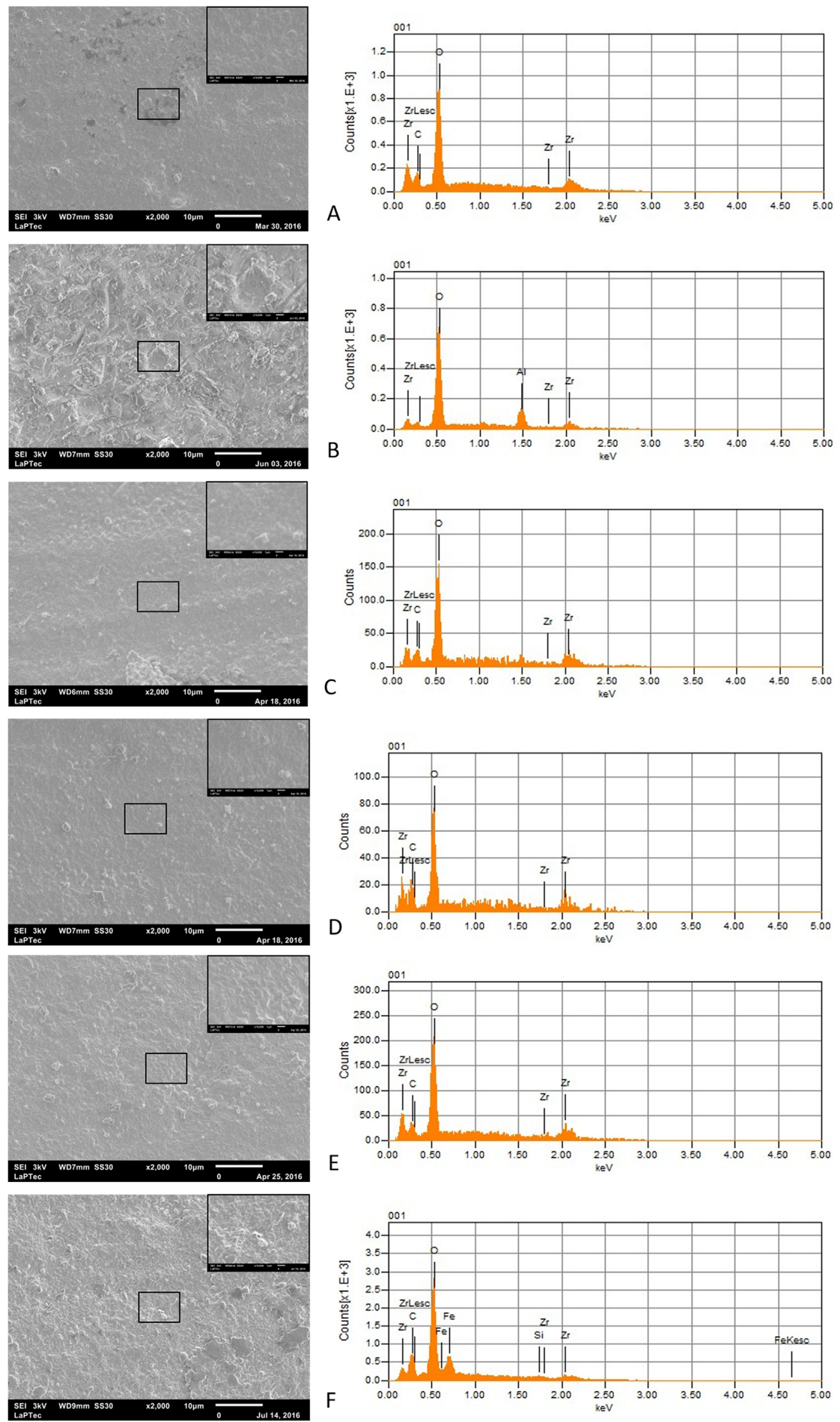


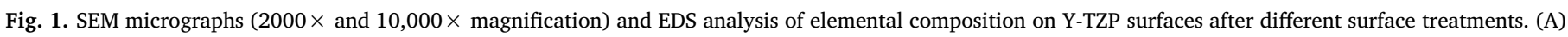

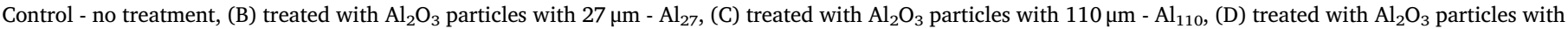
$250 \mu \mathrm{m}-\mathrm{Al}_{250}$, (E) treated with liner - $\mathrm{L}$ and $(\mathrm{F})$ treated with plasma - P.

smooth surface (Fig. 2E), whilst a similar surface was presented for both groups $\mathrm{C}$ and $\mathrm{P}$ (Fig. 2F).

PECVD treatment did not change the roughness values of Y-TZP when compared with the control group ( $\mathrm{Ra}, \mathrm{p}=0.138$; $\mathrm{Rq}, \mathrm{p}=0.172$; Rt, $\mathrm{p}=0.231 ; \mathrm{Rz}, \mathrm{p}=0.591$ ). The airborne-particle abrasion with $110 \mu \mathrm{m}$ and $250 \mu \mathrm{m} \mathrm{Al} \mathrm{O}_{2}$ particles and liner increased the surface roughness of Y-TZP ( $p<0.05$ vs control) (Fig. 3). All surface treatments increased the Y-TZP surface-free energy values ( $p<0.05$ vs control), except for $\mathrm{Al}_{27}$ (Fig. 4).

\subsection{Shear bond strength of the $Y$-TZP/veneering ceramic interface}

The mean and standard deviation of SBS values between the Y-TZP and the veneering ceramic before and after thermocycling are shown in Table 2. The two-way ANOVA analysis showed that the surface treatment was significant to the SBS values $(\mathrm{p}<0.001)$. However, the testing period $(\mathrm{p}=0.069)$ and the interaction between surface treatment and the testing period $(\mathrm{p}=0.069)$ were not significant. Therefore, post hoc analysis was performed considering the surface treatment independent of the period (before and after thermocycling), and results are shown in Fig. 5. PECVD treatment increased the SBS values of the Y$\mathrm{TZP} /$ veneering ceramic interface when compared with all other groups ( $\mathrm{p}<0.05$ ), except the $\mathrm{Al}_{27}$ group ( $\mathrm{p}=0.107$ ).

Both mixed and adhesive failures were observed at the Y-TZP/veneering ceramic interface. Regardless of the testing period, only mixed failures $(100 \%)$ occurred in the C, L and P groups. Adhesive failures were observed in the $\mathrm{Al}_{110}$ group, in both before $(10 \%)$ and after thermocycling (20\%), and in the $\mathrm{Al}_{250}$ group before thermocycling (20\%) (Fig. 6). After thermocycling, some premature failures $(10 \%)$ occurred at the Y-TZP/veneering ceramic interface.

SEM micrographs of the morphology of fractured surfaces showed mixed failure modes, cohesive failure in the veneering ceramic and adhesive failure in the zirconia/veneering interface (Fig. 7A-D). In Fig. 7A-B, the adhesive failure is represented in both veneering ceramic and zirconia, showing smooth surfaces without residual parts of the other material. Fig. 7C represents the mixed failure in the veneering ceramic, and the arrow highlights the crack initiation. Fig. 7D demonstrates the mixed failure on the zirconia surfaces, and the veneering ceramic remaining $(\mathrm{VC})$ on the Y-TZP surfaces $(\mathrm{Z})$ can be identified.

\section{Discussion}

The results of the present study indicate that the research hypothesis, that the PECVD treatment would promote alterations in the Y-TZP surface characteristics and affect SBS values, was accepted. The film deposited by PECVD significantly increased zirconia surface-free energy, as well as the SBS between Y-TZP and the nano-fluorapatite glass ceramic, without affecting the surface roughness of the zirconia.

The reasons for the high SBS values obtained with the PECVD treatment were two-fold: surface cleaning and the degree of connection promoted by the film composition and general characteristics. Also, the SBS was improved due to the compatibility of the film with the Y-TZP and ceramic surfaces, representing a mechanically strong interlayer. In a previous study [33], $\mathrm{CH}_{4}$ and HMDSO film deposition was characterised as diamond-like carbon (DLC) with $\mathrm{SiO}_{\mathrm{x}}$ incorporation (DLC:SiOx). These films combined a cohesive structure and high mechanical properties, explaining the high SBS presented by the plasma (P) group.

The objective of PECVD treatment was to create an intermediate layer between Y-TZP and the veneering ceramic, which adhered well to both sides having structural strength. In this scenario, the plasma cleaning procedure has a beneficial role. Ar plasma sputtering is able to enhance the hydrophilicity of a surface [34] by a superficial cleaning and surface activation that increase wettability and surface-free energy [22]. Conversely, film deposition under ionic bombardment, promoted by sample polarisation $(500 \mathrm{~V})$, can induce some element penetration of the Y-TZP surface in the early stages of the process. The incorporation of $\mathrm{Si}$ (from HMDSO fragments) and $\mathrm{C}$ (from $\mathrm{CH}_{4}$ fragments) in the $\mathrm{Y}$ TZP surface region decreases the mismatches of mechanical/thermal properties between the film and the substrate, thus increasing the physical stability of the interlayer. These factors directly affect SBS between the ceramic substrates. In addition, the dilution of the Y-TZP with the film constitutents induces strong chemical bonds, providing a film with extra chemically reactive regions without causing damage to the Y-TZP structure [2, 25, 26].

The plasma deposition in atmospheres of HMDSO and Ar mixtures has been previously described [25] and presented good results in terms of mantaining surface topography whilst improving surface-free energy of dental glass ceramics. It is important to observe that the final step of the treatment, in which HMDSO flux of the plasma feed is interrupted, with only Ar remaining, produces ion bombardment of the sample surface with Ar-positive ions. The energy deposited in such collision generates, among other things, bond fragmentation with emission of groups weakly connected to the structure. This phenomenon creates, in the newly deposited film, pendant bonds, which are very prone to react with species of layers or compounds coming into contact with them. This explains both the elevation in surface-free energy, when atmospheric polar groups react with these bonds, as well as the improvement in the connectivity between zirconia and the veneering ceramic. Therefore, the activation of the plasma-deposited films is indicated as a relevant procedure for the establishment of more and stronger connections between and among the different materials. The plasma treatment with $\mathrm{CH}_{4}$ has also been used [35] to increase the surface-free energy of metals and polymers. Thus, the deposition conditions used herein created a hydrophilic film surface with structural strength and adhering well to the zirconia, relevant issues as one considers the improvement in the conectivity between zirconia and veneering ceramic. As surface-free energy is not the sole parameter for defining SBS, its effect must be evaluated. The plasma group presented the greatest SBS when compared with the other groups, being statistically similar only to the $\mathrm{Al}_{27}$ group. However, the necessity of a thorough investigation of the superficial effects of both treatments on zirconia surfaces is worth emphasising, as alumina blasting, even with smaller particles, can cause surface damage [10,36], which does not occur with the PECVD treatment.

A recent review [23] about the use of plasma deposition in dentistry reported that this treatment is effective in the modification of surface chemical properties of several restorative materials, besides being considered an aid mechanism in the bonding of these materials to dental substrate. Yet, it has been reported that the zirconia treated with film deposition presented low rates of carbon (C) on its surface, attributed to organic contaminants [2, 21, 23].

Through topographic and roughness analyses, it is possible to observe the maintenance of the surface topography and surface characteristics of zirconia after PECVD treatment. A previous study [22] showed that the plasma treatment was unable to promote significant alterations in the topography of zirconia, whilst it is a more effective method than the application of liner for the improvement of bonding between Y-TZP and veneering ceramic.

Due to the composition and properties of liners, being similar to those of veneering ceramics, a more effective bond is expected between the ceramic/liner interface than between the zirconia/liner interface 

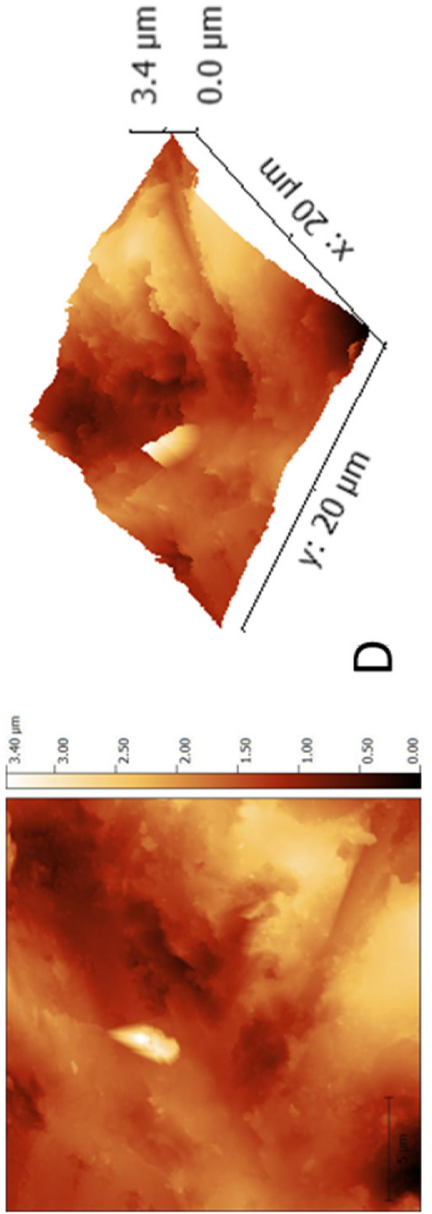

틀 통

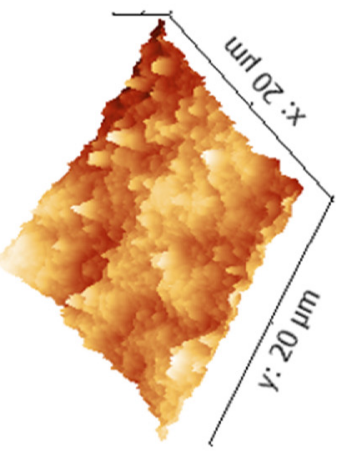

$\varangle$

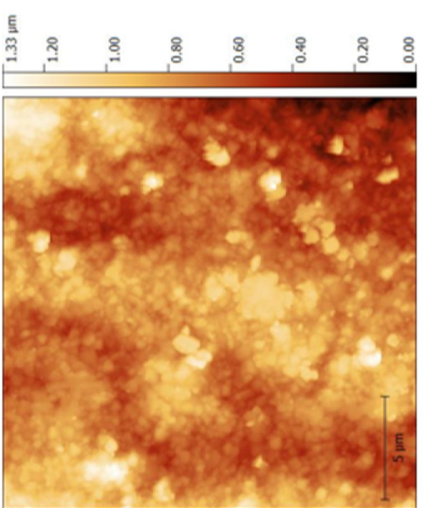

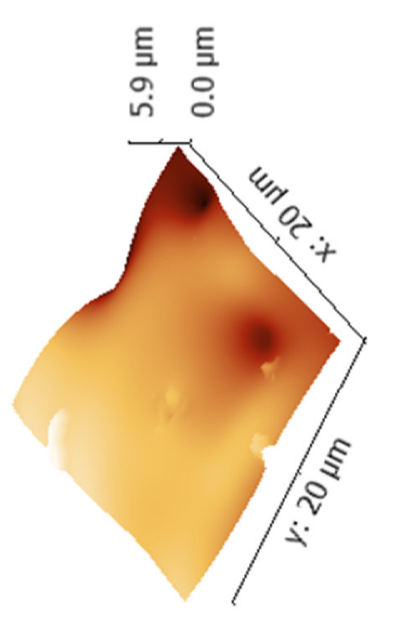

山
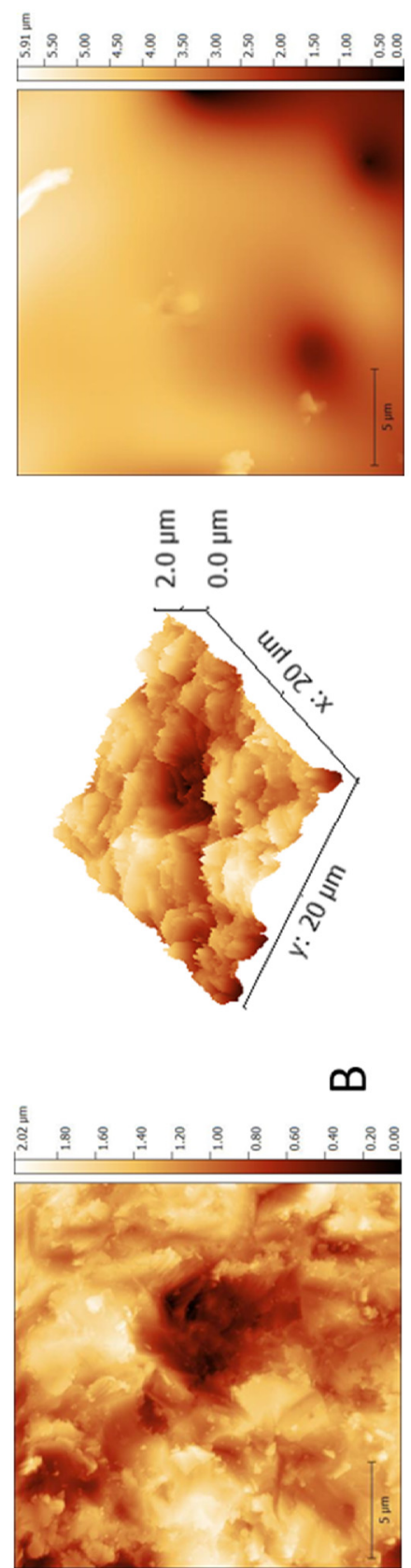

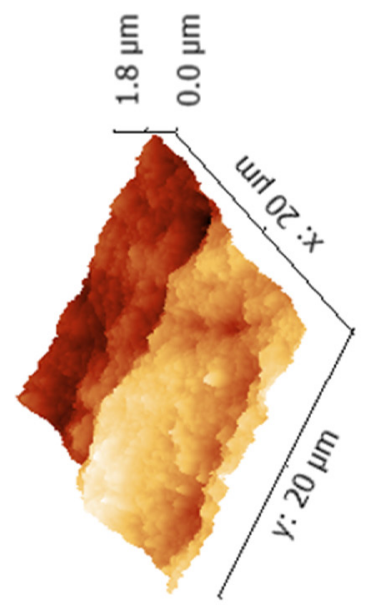

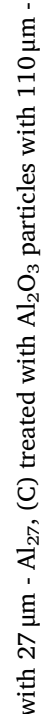
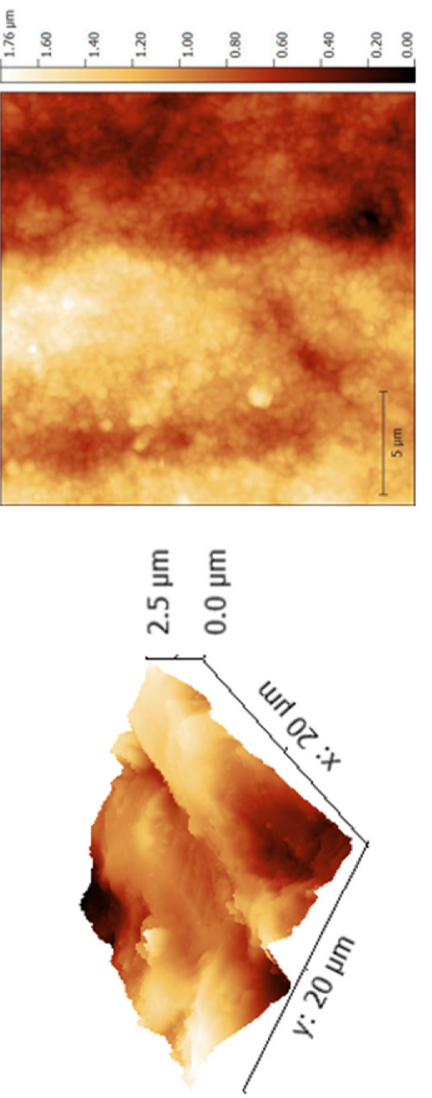

을

过

ठัँ

ङ

这氙

$\Xi$

苟.

苛苞

可

幽

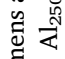

$\cup$ 竞自

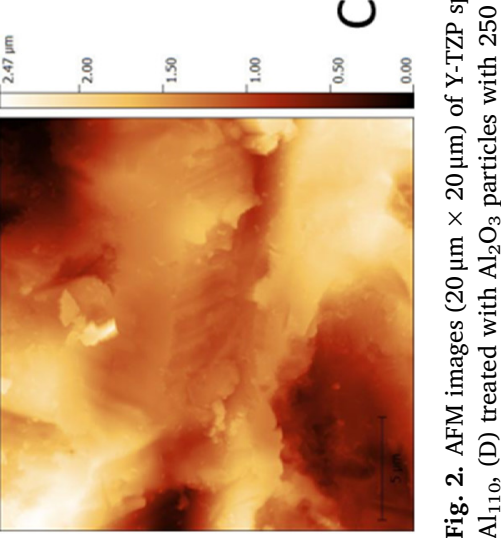




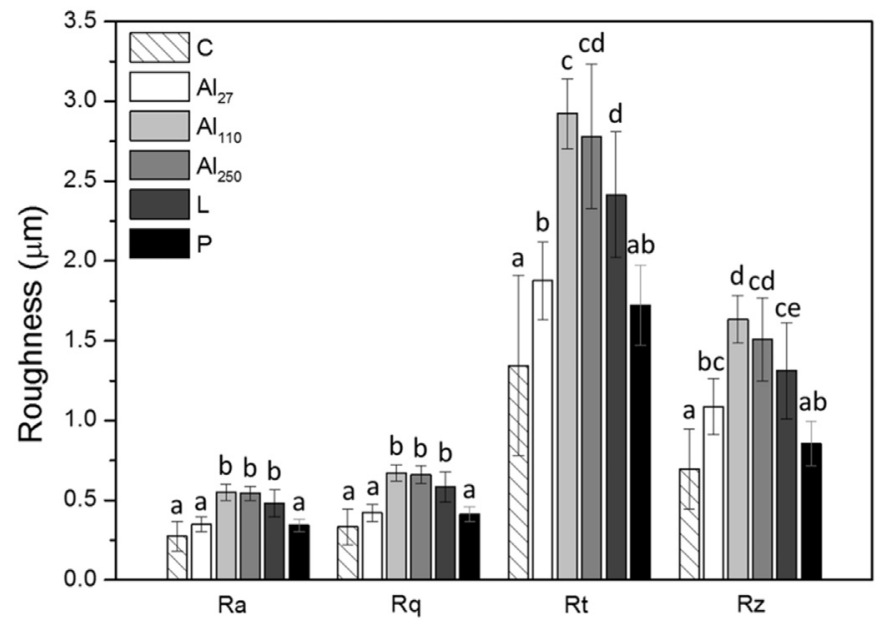

Fig. 3. Surface roughness of Y-TZP (Ra, Rq, Rt and Rz) after different surface treatments (mean values and stdev in $\mu \mathrm{m}$ ). Different letters represent statistically significant differences among groups within each roughness parameter (p < 0.05; Tukey's HSD test). (C) control; $\left(\mathrm{Al}_{27}\right)$ aluminum oxide particles with $27 \mu \mathrm{m} ;\left(\mathrm{Al}_{110}\right)$ aluminum oxide particles with $110 \mu \mathrm{m} ;\left(\mathrm{Al}_{250}\right)$ aluminum oxide particles with $250 \mu \mathrm{m}$; (L) liner; (P) plasma.

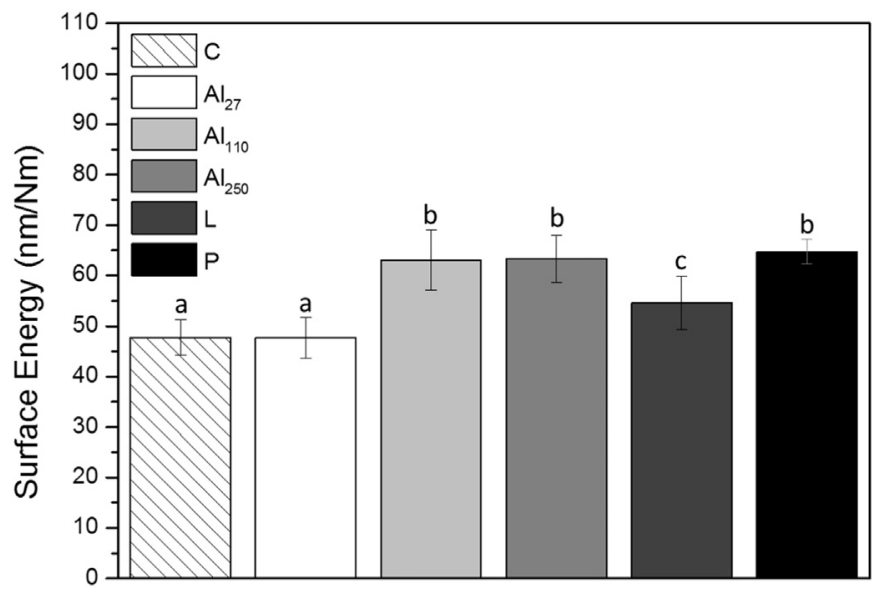

Fig. 4. Surface-free energy of Y-TZP specimens after different surface treatments (mean values with stdev in $\mathrm{nM} / \mathrm{Nm}$ ). Different letters represent statistically significant differences among groups ( $\mathrm{p}<0.05$; Tukey's HSD test). (C) control; $\left(\mathrm{Al}_{27}\right)$ aluminum oxide particles with $27 \mu \mathrm{m}$; $\left(\mathrm{Al}_{110}\right)$ aluminum oxide particles with $110 \mu \mathrm{m}$; $\left(\mathrm{Al}_{250}\right)$ aluminum oxide particles with $250 \mu \mathrm{m}$; (L) liner; (P) plasma.

Table 2

Means (stdev) of SBS values (in MPa) between Y-TZP and veneering ceramic before and after thermocycling as a function of different surface treatments.

\begin{tabular}{lll}
\hline Groups & \multicolumn{2}{l}{ SBS (MPa) } \\
\cline { 2 - 3 } & Before thermocycling & After thermocycling \\
\hline $\mathrm{C}$ & $10.05(1.27)$ & $11.62(2.32)$ \\
$\mathrm{Al}_{27}$ & $12.25(2.23)$ & $13.67(2.56)$ \\
$\mathrm{Al}_{110}$ & $12.59(2.13)$ & $9.41(3.92)$ \\
$\mathrm{Al}_{250}$ & $9.23(0.68)$ & $8.65(3.71)$ \\
$\mathrm{L}$ & $11.39(2.45)$ & $12.31(3.86)$ \\
$\mathrm{P}$ & $15.99(2.62)$ & $14.73(3.04)$ \\
\hline
\end{tabular}

Note: (C) control; $\left(\mathrm{Al}_{27}\right)$ aluminum oxide particles with $27 \mu \mathrm{m}$; $\left(\mathrm{Al}_{110}\right)$ aluminum oxide particles with $110 \mu \mathrm{m} ;\left(\mathrm{Al}_{250}\right)$ aluminum oxide particles with $250 \mu \mathrm{m}$; (L) liner; (P) plasma.

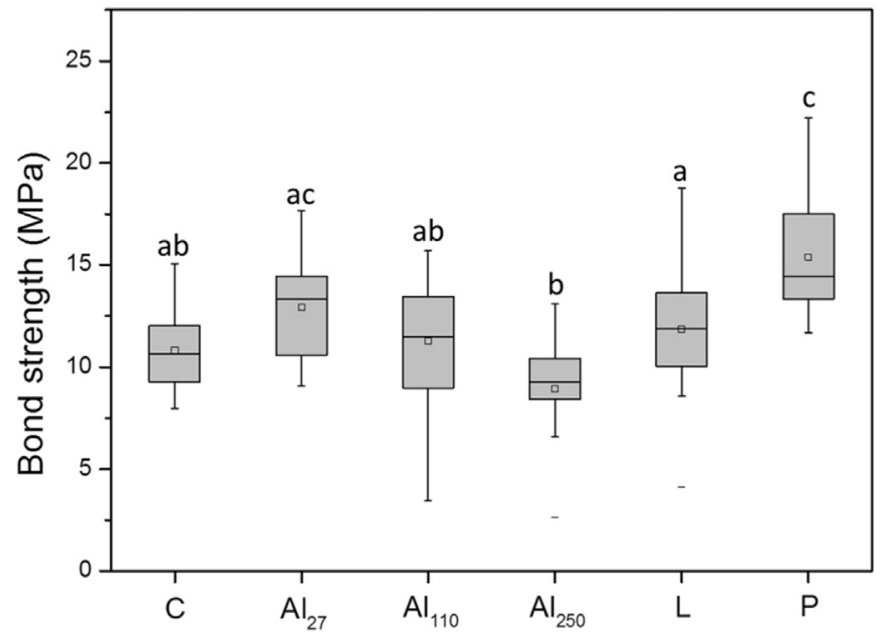

Fig. 5. Box plot of the SBS values (in MPa) between Y-TZP and veneering ceramic as a function of different surface treatments independent of the testing period (before and after thermocycling). The bottom and the top of the box represent the 1st and 3rd quartiles, respectively. Inside the box, the band represents the median (2nd quartile) and the square represents the mean value. The ends of the whiskers represent the minimum and maximum values. Outliers are represented by the hyphen symbol outside the box. Different letters represent statistically significant differences among groups $(\mathrm{p}<0.05$; Tukey's HSD test). (C) control; $\left(\mathrm{Al}_{27}\right)$ aluminum oxide particles with $27 \mu \mathrm{m} ;\left(\mathrm{Al}_{110}\right)$ aluminum oxide particles with $110 \mu \mathrm{m} ;\left(\mathrm{Al}_{250}\right)$ aluminum oxide particles with $250 \mu \mathrm{m}$; (L) liner; (P) plasma.

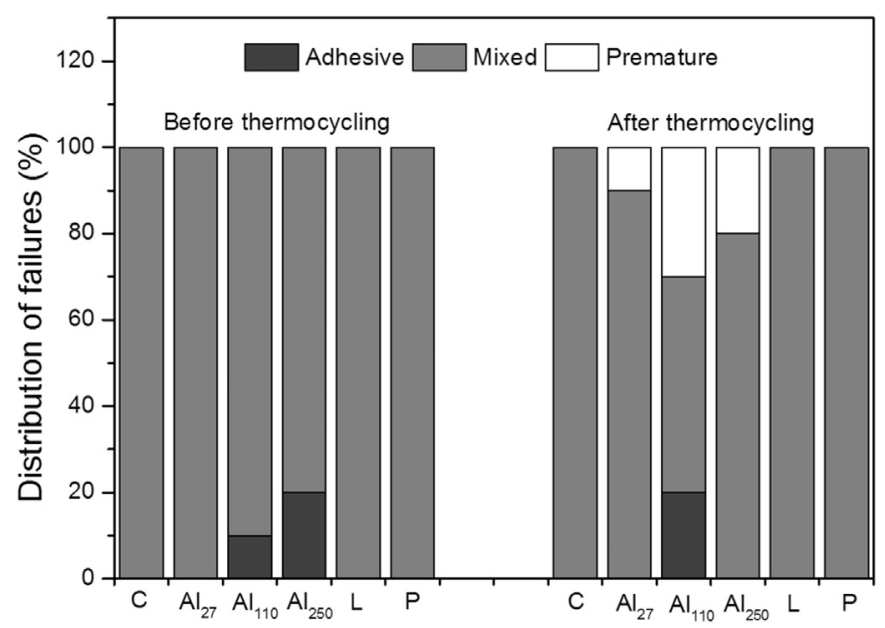

Fig. 6. Distribution of failures between Y-TZP and veneering ceramic after bond strength testing, before and after thermocycling. (C) control; $\left(\mathrm{Al}_{27}\right)$ aluminum oxide particles with $27 \mu \mathrm{m}$; $\left(\mathrm{Al}_{110}\right)$ aluminum oxide particles with $110 \mu \mathrm{m}$; $\left(\mathrm{Al}_{250}\right)$ aluminum oxide particles with $250 \mu \mathrm{m}$; (L) liner; (P) plasma.

$[7,18]$. However, owing to its capacity to increase the wettability of zirconia, the liner is used as an intermediate layer between zirconia and veneering ceramic [7]. Previous studies [7, 18, 22], however, have reported that liners may indeed hinder the bonding between zirconia and veneering material, increasing the probability of interfacial failure between the zirconia and veneering ceramic. In the present study, liner treatment did not actually inhibit bonding of veneering material to zirconia, but also did not improve the SBS in comparison with the control group.

A recent study [37] evaluated the influence on wettability of feldspathic veneer with different sizes of aluminum particles (50 and $250 \mu \mathrm{m}$ ) and concluded that the rougher the ceramic surface, the lower its wettability. This characteristic could affect the Y-TZP/veneering ceramic interface. This statement agrees with what was found in our 

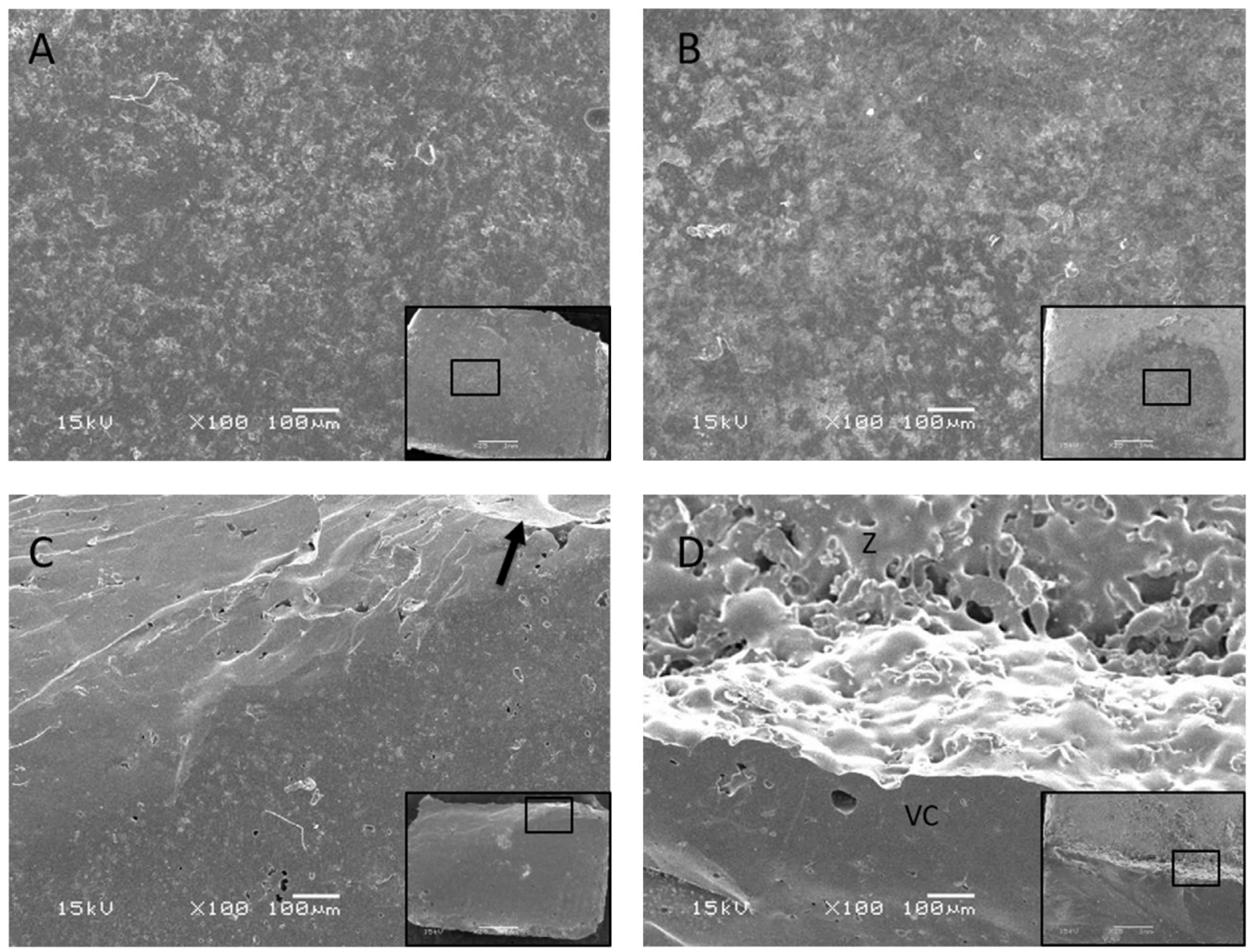

Fig. 7. SEM micrographs ( $25 \times$ and $100 \times$ magnification). (A) Adhesive failure in veneering ceramic. (B) Adhesive failure in zirconia. (C) Mixed failure in ceramic. (D) Mixed failure in zirconia. Arrow indicates initial region of cohesive failure at the veneering ceramic surface. $\mathrm{Z}=$ zirconia; $\mathrm{VC}=$ veneering ceramic.

study, that when the airborne-particle abrasion with $\mathrm{Al}_{2} \mathrm{O}_{3}$ particles of $110 \mu \mathrm{m}$ and $250 \mu \mathrm{m}$ was performed, the greatest roughness values were associated with the lowest SBS values. However, our results also showed that surface-free energy increase cannot be considered the single factor responsible for improved SBS between Y-TZP and veneering ceramic, as the $\mathrm{Al}_{110}$ and $\mathrm{Al}_{250}$ groups presented high results of surface-free energy, but SBS results were either similar to or lower than those presented by the control group. Conversely, the $\mathrm{Al}_{27}$ group showed small results of surface-free energy, but high values for SBS. The greater roughness presented by $\mathrm{Al}_{110}$ and $\mathrm{Al}_{250}$ groups was related to the sizes of the particles used, as the time, pressure and distance were standardised for all groups that used airborne-particle abrasion. When the alumina-blasted images obtained by AFM were compared, it was possible to observe that the depths of the depressions/valleys increased gradually as a function of the sizes of the $\mathrm{Al}_{2} \mathrm{O}_{3}$ particles. The alterations in the surface profiles and roughness values of the airborne-particle abrasion groups were due to the mechanical action of the particles on the surfaces of the specimens, and not to the impregnation of any particles on the surface. Yet, they were the only groups to present adhesive failures after the application of the glass ceramic. The use of larger $\mathrm{Al}_{2} \mathrm{O}_{3}$ particles in airborne-particle abrasion generated lower rates of zirconia survival $[10,38]$, with delamination of porcelain, because the impact of the $\mathrm{Al}_{2} \mathrm{O}_{3}$ particles on zirconia surface generated a zone of compressive stresses and also generated micro-cracks that can propagate under cyclic loading [39]. However, when smaller particles were used, it was possible to modify the surface without inducing excessive damage and, consequently, less concentration of stress on the treated surface $[10,36]$.

Fractures of the veneering ceramic may also occur more frequently, as occurred in this study, where adhesive and premature failures were encountered only in groups treated with airborne-particle abrasion, regardless of the sizes of the particles. This suggests that the detrimental effect of stress accumulation in the Y-TZP increased with thermocycling. Thus, airborne-particle abrasion could negatively influence the SBS survival rate between these materials. Also, the combination of airborne-particle abrasion with long periods of thermocycling could generate a lower survival rate of bond between Y-TZP/veneering ceramic, as premature failures were found only in the abraded groups after thermocycling. This was indeed observed in the SEM and AFM images for the $\mathrm{Al}_{27}$ group, as surface changes observed on zirconia and the SBS values were superior when compared with those of the groups blasted with larger particles. In the EDS analysis of the blasted groups, only the $\mathrm{Al}_{27}$ group presented $\mathrm{Al}$ particle impregnation, whilst $\mathrm{Al}_{110}$ and $\mathrm{Al}_{250}$ groups did not present $\mathrm{Al}$ on the surface. This may be explained by the sizes of the particles used in each group, as smaller particles, such as those used in the $\mathrm{Al}_{27}$ group, could be more easily entrapped on the zirconia surface due to the combination of roughness and relatively high pressure of the airborne-particle abrasion.

Different tests are performed to evaluate the SBS between Y-TZP and veneering ceramic, such as the shear strength test, the three- or four-point bending test, the biaxial flexural strength test or the direct compression strength test [14]. It must be considered that SBS analysis by shear strength testing presents limitations when compared with real clinical situations. Nonetheless, it is one of the most widely used methods when the objective is to evaluate the interfacial strengths of dental materials, requiring caution in the interpretation of the results [24]. Thus, the shear strength test proposed by Schmitz \& Schulmeyer [30], and used in this study, can be considered effective for evaluation 
of the SBS between two ceramic materials [32], as the stresses generated during the test are mainly applied to the interface between the materials, creating a uniform distribution of interfacial tensions [32, 40]. This is confirmed by the distribution of mixed failures throughout the experimental groups, with the adhesive component of the mixed failure indicating that the stresses were incited at the bonding interface between the two substrates.

It is known that the physical and chemical properties of ceramic structures like zirconia are maintained when zirconia is exposed to the diverse conditions of the oral environment [41]. Thus, even after the long period of thermal fatigue $(20,000$ cycles), the stability of the material was observed, not only for the ceramic properties, but also for the shear strength at the interface between the two materials, regardless of the surface treatment performed.

It is critical to emphasise that, despite the promising and satisfactory laboratory results presented by this study, few studies have been performed evaluating the effect of this treatment on the performance of dental materials. Our study is limited by being an in vitro study, and the findings observed here should not be extrapolated to the clinical scenario without validation of the PECVD treatment for interfacial bonding between the zirconia core and the veneering ceramic. The characterisation of plasma film deposition under mechanical fatigue of crowns/ prostheses is therefore strongly suggested.

\section{Conclusion}

It can be concluded that the film deposited by PECVD was shown to be a safe surface treatment from a structural point of view, in addition to generating high shear bond strength results between Y-TZP and veneering ceramic even after a thermocycling treatment, indicating that the PECVD treatment presents a lasting effect.

\section{Acknowledgements}

The authors thank the São Paulo Reseacrh Foundation (FAPESP) (Grant numbers 2015/11412-3 and 2015/10826-9) for the financial aid in the development of this project.

The authors report no conflicts of interest.

\section{References}

[1] S. Reich, S. Gozdowski, L. Trentzsch, R. Frankenberger, U. Lohbauer, Marginal fit of heat-pressed vs. CAD/CAM processed all-ceramic onlays using a milling unit prototype, Oper. Dent. 33 (2008) 644-650, http://dx.doi.org/10.2341/07-162.

[2] G.B. Valverde, P.G. Coelho, M.N. Janal, F.C. Lorenzoni, R.M. Carvalho, V.P. Thompson, et al., Surface characterisation and bonding of Y-TZP following non-thermal plasma treatment, J. Dent. 41 (2013) 51-59, http://dx.doi.org/10. 1016/j.jdent.2012.10.002.

[3] G.J. Christensen, Porcelain-fused-to-metal versus zirconia-based ceramic restorations, J. Am. Dent. Assoc. 140 (2009) 1036-1039.

[4] C. Monaco, A. Tucci, L. Esposito, R. Scotti, Adhesion mechanisms at the interface between Y-TZP and veneering ceramic with and without modifier, J. Dent. 42 (2014) 1473-1479, http://dx.doi.org/10.1016/j.jdent.2014.07.019.

[5] Y.T. Jian, T.Y. Tang, M.V. Swain, X.D. Wang, K. Zhao, Effect of core ceramic grinding on fracture behaviour of bilayered zirconia veneering ceramic systems under two loading schemes, Dent. Mater. 32 (2016) 1453-1463, http://dx.doi.org/ 10.1016/j. dental.2016.06.007.

[6] M.N. Aboushelib, N. de Jager, C.J. Kleverlaan, A.J. Feilzer, Microtensile bond strength of different components of core veneered all-ceramic restorations, Dent. Mater. 21 (2005) 984-991.

[7] H.J. Kim, H.P. Lim, Y.J. Park, M.S. Vang, Effect of zirconia surface treatments on the shear bond strength of veneering ceramic, J. Prosthet. Dent. 105 (2011) 315-322, http://dx.doi.org/10.1016/S0022-3913(11)60060-7.

[8] P.F. Manicone, P. Rossi Iommetti, L. Raffaelli, An overview of zirconia ceramics: basic properties and clinical applications, J. Dent. 35 (2007) 819-826.

[9] I. Denry, J.R. Kelly, State of the art of zirconia for dental applications, Dent. Mater. 24 (2008) 299-307.

[10] M.N. Aboushelib, H. Wang, Influence of crystal structure on debonding failure of zirconia veneered restorations, Dent. Mater. 29 (2013) e97-e102, http://dx.doi. org/10.1016/j.dental.2013.04.008.

[11] V. Preis, K. Grumser, S. Schneider-Feyrer, M. Behr, M. Rosentritt, Cycle-dependent in vitro wear performance of dental ceramics after clinical surface treatments, J. Mech. Behav. Biomed. Mater. 53 (2016) 49-58, http://dx.doi.org/10.1016/j. jmbbm.2015.08.009.

[12] M.N. Aboushelib, C.J. Kleverlaan, A.J. Feilzer, Effect of zirconia type on its bond strength with different veneer ceramics, J. Prosthodont. 17 (2008) 401-408, http:// dx.doi.org/10.1111/j.1532-849X.2008.00306.x.

[13] J.W. McLean, Evolution of dental ceramics in the twentieth century, J. Prosthet. Dent. 85 (2001) 61-66.

[14] M. Doi, K. Yoshida, M. Atsuta, T. Sawase, Influence of pre-treatments on flexural strength of zirconia and debonding crack-initiation strength of veneered zirconia, J. Adhes. Dent. 13 (2011) 79-84, http://dx.doi.org/10.3290/j.jad.a18239.

[15] C. Wang, L.N. Niu, Y.J. Wang, K. Jiao, Y. Liu, W. Zhou, et al., Bonding of resin cement to zirconia with high pressure primer coating, PLoS One 9 (2014) e101174, , http://dx.doi.org/10.1371/journal.pone.0101174.

[16] J. Fischer, P. Grohmann, B. Stawarczyk, Effect of zirconia surface treatments on the shear strength of zirconia/veneering ceramic composites, Dent. Mater. J. 27 (2008) 448-454

[17] D. Liu, J.P. Matinlinna, J.K. Tsoi, E.H. Pow, T. Miyazaki, Y. Shibata, et al., A new modified laser pretreatment for porcelain zirconia bonding, Dent. Mater. 29 (2013) 559-565, http://dx.doi.org/10.1016/j.dental.2013.03.002.

[18] G. Wang, S. Zhang, C. Bian, H. Kong, Interface toughness of a zirconia-veneer system and the effect of a liner application, J. Prosthet. Dent. 112 (2014) 576-583, http://dx.doi.org/10.1016/j.prosdent.2013.12.010.

[19] M. Wolfart, F. Lehmann, S. Wolfart, M. Kern, Durability of the resin bond strength to zirconia ceramic after using different surface conditioning methods, Dent. Mater. 23 (2007) 45-50.

[20] M.N. Aboushelib, A.J. Feilzer, C.J. Kleverlaan, Bonding to zirconia using a new surface treatment, J. Prosthodont. 19 (2010) 340-346, http://dx.doi.org/10.1111/ j.1532-849X.2010.00575.X.

[21] N.R. Silva, P.G. Coelho, G.B. Valverde, K. Becker, R. Ihrke, A. Quade, et al., Surface characterization of Ti and Y-TZP following non-thermal plasma exposure, J Biomed Mater Res B Appl Biomater 99 (2011) 199-206, http://dx.doi.org/10.1002/jbm.b. 31887.

[22] M.-H. Lee, K.B. Min, S.J. Son, T.-Y. Kwon, Influence of different post-plasma treatment storage conditions on the shear bond strength of veneering porcelain to zirconia, Materials 9 (2016) 43, http://dx.doi.org/10.3390/ma9010043.

[23] Y. Liu, Q. Liu, Q.S. Yu, Y. Wang, Nonthermal atmospheric plasmas in dental restoration, J. Dent. Res. 95 (2016) 496-505, http://dx.doi.org/10.1177/ 0022034516629425 .

[24] L. Canullo, C. Micarelli, L. Bettazzoni, A. Magnelli, P. Baldissara, Shear bond strength of veneering porcelain to zirconia after argon plasma treatment, Int. J. Prosthodont. 27 (2014) 137-139, http://dx.doi.org/10.11607/ijp.3722.

[25] A.J. Vechiato-Filho, D.M. dos Santos, M.C. Goiato, R.A. de Medeiros, A. Moreno L.R. Bonatto, et al., Surface characterization of lithium disilicate ceramic after nonthermal plasma treatment, J. Prosthet. Dent. 112 (2014) 1156-1163, http://dx. doi.org/10.1016/j.prosdent.2014.02.021.

[26] A.J. Vechiato-Filho, I. da Silva Vieira Marques, D.M. dos Santos, A.O. Matos, E.C. Rangel, N.C. da Cruz, et al., Effect of nonthermal plasma treatment on surface chemistry of commercially-pure titanium and shear bond strength to autopolymerizing acrylic resin, Mater. Sci. Eng. C Mater. Biol. Appl. 60 (2016) 37-44, http://dx.doi.org/10.1016/j.msec.2015.11.008.

[27] G.J. Han, S.N. Chung, B.H. Chun, C.K. Kim, K.H. Oh, B.H. Cho, Effect of the applied power of atmospheric pressure plasma on the adhesion of composite resin to dental ceramic, J. Adhes. Dent. 14 (2012) 461-469, http://dx.doi.org/10.3290/j.jad. a25688.

[28] R. Amaral, M. Ozcan, L.F. Valandro, I. Balducci, M.A. Bottino, Effect of conditioning methods on the microtensile bond strength of phosphate monomer-based cement on zirconia ceramic in dry and aged conditions, J Biomed Mater Res B Appl Biomater 85 (2008) 1-9.

[29] H. Yamaguchi, S. Ino, N. Hamano, S. Okada, T. Teranaka, Examination of bond strength and mechanical properties of Y-TZP zirconia ceramics with different surface modifications, Dent. Mater. J. 31 (2012) 472-480.

[30] K. Schmitz, H. Schulmeyer, Determination of the adhesion of dental metal-porcelain bonding systems, Dent. Labor. (Munich) 23 (1975) 1416-1420.

[31] T. Sun, L. Shao, B. Deng, N. Wen, Shear bond strengths between ceramic cores and veneering ceramics of dental bi-layered ceramic systems and the sensitivity to thermocycling, Ceramics-Silikáty 56 (2012) 238-244.

[32] P.C. Guess, A. Kulis, S. Witkowski, M. Wolkewitz, Y. Zhang, J.R. Strub, Shear bond strengths between different zirconia cores and veneering ceramics and their susceptibility to thermocycling, Dent. Mater. 24 (2008) 1556-1557, http://dx.doi.org/ 10.1016/j.dental.2008.03.028.

[33] L. Zajíčková, V. Buršíková, Z. Kučerová, D. Franta, P. Dvořák, R. Šmíd, et al., Deposition of protective coatings in rf organosilicon discharges, Plasma Sources Sci. Technol. 16 (2007) S123-S132.

[34] M. Chen, Y. Zhang, M. Sky Driver, A.N. Caruso, Q. Yu, Y. Wang, Surface modification of several dental substrates by non-thermal, atmospheric plasma brush, Dent. Mater. 29 (2013) 871-880, http://dx.doi.org/10.1016/j.dental.2013.05.002.

[35] N.C. Cruz, E.C. Rangel, G.Z. Gadioli, R.P. Mota, The influence of plasma composition on the properties of plasma treated biomaterials, MRS Proc. 672 (2001), http:// dx.doi.org/10.1557/PROC-672-03.35.

[36] B. Yang, A. Barloi, M. Kern, Influence of air-abrasion on zirconia ceramic bonding using an adhesive composite resin, Dent. Mater. 26 (2010) 44-50, http://dx.doi. org/10.1016/j.dental.2009.08.008.

[37] M.T. Marefati, A.M. Hadian, T. Hooshmand, B.E. Yekta, R. Koohkan, Wettability of zirconia by feldspathic veneer in dental restorations: effect of firing atmosphere and surface roughness, Ceram. Int. 44 (2018) 4307-4312.

[38] H. Wang, M.N. Aboushelib, A.J. Feilzer, Strength influencing variables on CAD/ CAM zirconia frameworks, Dent. Mater. 24 (2008) 633-638. 
[39] H.I. Yoon, I.S. Yeo, Y.J. Yi, S.H. Kim, J.B. Lee, J.S. Han, Effect of surface treatment and liner material on the adhesion between veneering ceramic and zirconia, J. Mech. Behav. Biomed. Mater. 40 (2014) 369-374, http://dx.doi.org/10.1016/j jmbbm.2014.09.017.

[40] K.J. Anusavice, P.H. Dehoff, C.W. Fairhurst, Comparative evaluation of ceramic- metal bond tests using finite element stress analysis, J. Dent. Res. 59 (1980) 608-613.

[41] A. Della Bona, Characterizing ceramics and the interfacial adhesion to resin: I - the relationship of microstructure, composition, properties and fractography, J. Appl. Oral Sci. 13 (2005) 1-9. 